Article

\title{
An ISE-based On-Site Soil Nitrate Nitrogen Detection System
}

\author{
Yanhua Li ${ }^{1}$, Qingliang Yang ${ }^{1}$, Ming Chen ${ }^{1}$, Maohua Wang ${ }^{1,2}$ and Miao Zhang ${ }^{1,2, *}$ \\ 1 Key Laboratory on Modern Precision Agriculture System Integration Research of Ministry of Education, \\ China Agricultural University, Beijing 100083, China; 15001228421@163.com (Y.L.); \\ qingliangyang@cau.edu.cn (Q.Y.); mercury@cau.edu.cn (M.C.); wangmh@cau.edu.cn (M.W.) \\ 2 Key Lab of Agricultural Information Acquisition Technology of Ministry of Agriculture and Rural Affairs, \\ China Agricultural University, Beijing 100083, China \\ * Correspondence: zhangmiao@cau.edu.cn
}

Received: 20 August 2019; Accepted: 23 October 2019; Published: 28 October 2019

check for updates

\begin{abstract}
Soil nitrate-nitrogen $\left(\mathrm{NO}_{3}{ }^{-}-\mathrm{N}\right)$ is one of the primary factors used to control nitrogen topdressing application during the crop growth period. The ion-selective electrode (ISE) is a promising method for rapid lower-cost in-field detection. Due to the simplification of sample preparation, the accuracy and stability of ISE-based in-field detection is doubted. In this paper, a self-designed prototype system for on-site soil $\mathrm{NO}_{3}{ }^{-}-\mathrm{N}$ detection was developed. The procedure of spinning centrifugation was used to avoid interference from soil slurry suspension. A modified Nernstian prediction model was quantitatively characterized with outputs from both the ISE and the soil moisture sensor. The measurement accuracy of the sensor fusion model was comparable with the laboratory ISE detections with standard sample pretreatment. Compared with the standard spectrometric method, the average absolute error (AE) and root-mean-square error (RMSE) were found to be less than 4.7 and $6.1 \mathrm{mg} / \mathrm{L}$, respectively. The on-site soil testing efficiency was $4-5 \mathrm{~min} / \mathrm{sample}$, which reduced the operation time by $60 \%$ compared with manual sample preparation. The on-site soil $\mathrm{NO}_{3}{ }^{-}-\mathrm{N}$ status was dynamically monitored for 42 consecutive days. The declining peak of $\mathrm{NO}_{3}{ }^{-}-\mathrm{N}$ was observed. In all, the designed ISE-based detection system demonstrated a promising capability for the dynamic on-site monitoring of soil macronutrients.
\end{abstract}

Keywords: on-site detection; ion-selective electrode (ISE); soil nitrate nitrogen $\left(\mathrm{NO}_{3}{ }^{-}-\mathrm{N}\right)$; soil moisture; sensor fusion

\section{Introduction}

The ion-selective electrode (ISE) transfers the ionic activity (or concentration) of the target ion dissolved in testing solutions into electromotive force (EMF). Theoretically, the measured EMF is related to the logarithm of the ionic activity according to the Nernst equation. Because of the importance of fertilizer in agricultural production, ISEs have been used in soil nitrate-nitrogen $\left(\mathrm{NO}_{3}{ }^{-} \mathrm{N}\right)$ analysis for more than half a century [1]. A prototype ISE based on an in-field nitrate monitoring system was first developed in 1994 and has been successively improved by Canadian researchers [2-4]. Soil samples were collected at a depth of $0-15 \mathrm{~cm}$ with an autosampler. GPS information was recorded at the same time. Programmable processes of soil bulk crushing and plant residue removing were designed. $\mathrm{NO}_{3}{ }^{-}-\mathrm{N}$ extraction was obtained by mixing the collected soil with de-ionized distilled water (DDW). The influence of soil texture was considered in sensor calibration. The fifth generation of the modified system demonstrated a satisfactory correlation with the standard method. An $\mathrm{R}^{2}$ of 0.92 was found in testing of 13 sets of samples. The problem of random ISE signal disturbance caused by soil slurry was claimed. 
In 2001, a portable ISE detection kit was developed for direct in-field measurement of soil chemical properties, including $\mathrm{pH}$, mineral $\mathrm{Na}^{+}$, mineral $\mathrm{K}^{+}$, and $\mathrm{NO}_{3}{ }^{-}-\mathrm{N}$ [5]. More than 500 soil samples were collected. However, the $\mathrm{NO}_{3}{ }^{-}-\mathrm{N}$ testing results demonstrated obvious variations from the standard spectrometric method. At the same time, researchers from the University of Missouri compared extractants for ISE-based soil macronutrient detection. Kelowna solution was chosen for the extraction of soil available $\mathrm{K}^{+}, \mathrm{PO}_{4}{ }^{3-}$, and $\mathrm{NO}_{3}{ }^{-}-\mathrm{N}$. Extracted soil solution was manually obtained using the recommended soil testing protocol. Feasibility was evaluated with 37 samples. ISE based laboratory soil $\mathrm{NO}_{3}{ }^{-}-\mathrm{N}$ detection demonstrated good accuracy with standard deviations ranging from 8.04 to $19.7 \mathrm{mg} / \mathrm{L}[6,7]$. Multiple studies were conducted on ISEs foron-the-go soil macronutrient monitoring by Adamchuk et al. For the purpose of achieving on-the-go soil testing, the "Direct Soil Measurement" (DSM) system was designed and then validated, updated, and commercially transformed in 2005. The ISEs of $\mathrm{NO}_{3}{ }^{-}, \mathrm{K}^{+}$, and $\mathrm{pH}$ were integrated to form the sensing unit. De-ionized(DI) water was applied for the cleaning of the ISE sensing array. Sensing results were directly collected without pretreatment operations of stirring and filtration. Compared with laboratory detection, the DSM results of $\mathrm{NO}_{3}{ }^{-}, \mathrm{K}^{+}, \mathrm{pH}$ were reported with coefficients of determination $\left(\mathrm{R}^{2}\right)$ of $0.41-0.51,0.61-0.62$, and around 0.9 , respectively [8,9]. Insufficient sample extraction was considered to be a possible reason for the unsatisfactory accuracy level. Sethuramasamyraja et al. improved the soil pretreatment process of the system by integrating a mechanical agitation operation into the sample extractant process. The "Integrated Agitated Soil Measurement" (ASM) results of the soil $\mathrm{pH}$ were comparable to laboratory testing with an $\mathrm{R}^{2}$ value of 0.99 . However, the predicted $\mathrm{NO}_{3}{ }^{-}$value still demonstrated great deviation from standard spectrometric results with an $\mathrm{R}^{2}$ value of 0.48 [10]. On the basis of the ASM system, the latest "On-the-Spot Analyzer" (OSA) system was developed for the simultaneously measurement of soil properties at a predefined soil depth. ISEs were brought into direct contact with the conditioned soil slurry, after the testing stand was moved to the experimental field and the topsoil was removed. Once sensors readings were retrieved, the analyzer was removed to another testing spot. Forty-five sets of surface topsoil samples with $\mathrm{NO}_{3}{ }^{-}-\mathrm{N}$ concentrations ranging from 0 to $30 \mathrm{mg} / \mathrm{kg}$ were measured on the spot. The correlation coefficient $R^{2}$ was increased to 0.87 [11]. The improved detection accuracy with the OSA system demonstrated promising potential for the achievement of automated measurements.

As far as we are concerned, most of the in-field soil testing discussed above involves reduced soil pretreatment operations due to the system's simplicity and efficiency. The testing error, produced by "soil particle suspension disturbance", reached a magnitude of $26.6 \mathrm{mg} / \mathrm{kg}$ with an average relative error of $50 \%$ according to our preliminary laboratory validation of ISE-based $\mathrm{NO}_{3}{ }^{-}-\mathrm{N}$ detection with 15 soil samples [12]. Besides, soil slurry would contaminate the membrane of ISE. The response slope of $\mathrm{NO}_{3}{ }^{-}$ISE was determined to be 44.4 and $25.4 \mathrm{mV} /$ decade after continuous testing for 4 and $12 \mathrm{~h}$, respectively [13]. Thus, it was necessary to obtain a transparent soil extract to enhance the accuracy and lifetime of the ISE. Pan et al. [14] tried to separate the clear soil $\mathrm{NO}_{3}{ }^{-}-\mathrm{N}$ extractant from sample slurry through the short-time process of spinning centrifugation. Seven soil samples were used for the optimization of the centrifugation operation. Clear soil extractant was obtained by spinning for $30 \mathrm{~s}$ at the centrifugation speed of $1000 \mathrm{rpm}$. Compared with the direct soil slurry detection, the $\mathrm{NO}_{3}{ }^{-}-\mathrm{N}$ detection relative error decreased from $64 \%$ to $5 \%$. Yanhua et al. [15] attempted to evaluate the effects of uncalibrated soil moisture on $\mathrm{NO}_{3}{ }^{-}-\mathrm{N}$ with six samples at the laboratory. The moisture of the tested samples was pre-manipulated to $2 \%-25 \%$. The ISE based $\mathrm{NO}_{3}{ }^{-}$ISE results were uniformly smaller than the standard spectrometric results when the influence of soil moisture was neglected. A soil moisture percentage of $25 \%$ produced a maximum absolute error of $30 \mathrm{mg} / \mathrm{kg}$. An error of no less than $5.0 \mathrm{mg} / \mathrm{kg}$ occurred even when the soil moisture was $5 \%$.

For the purpose of improving the accuracy of on-site soil $\mathrm{NO}_{3}{ }^{-} \mathrm{N}$ detection, a self-designed prototype system was designed by making use of the sensor fusion method. Both the $\mathrm{NO}_{3}{ }^{-}$ISE and soil moisture sensor were employed as the sensing unit. The specific objectives were, first, to integrate necessary soil pretreatment steps, e.g., sample weighting and extractant spinning centrifugation into 
an on-site testing bench. Second, we investigated a modified Nernst model for the prediction of soil $\mathrm{NO}_{3}{ }^{-}-\mathrm{N}$ with the real-time data provided by the ISE and the moisture sensor. Finally, we evaluated the feasibility of the system.

\section{Materials and Methods}

\subsection{Reagents and Apparatus}

A soil moisture sensor (ECH2O-5TE, Decagon, WA, USA) produced volumetric moisture readings that were used to determine the soil's net weight. The sensor was claimed to have a detection precision of $\pm 3 \% \mathrm{~m}^{3} / \mathrm{m}^{3}$. Reagents used were all Analytical grade. The testing solution was prepared with Deionized Water (Di-water). Standard soil chemical properties were provided by the soil testing center of the China Agricultural University with commercial analytical instruments. Detection was carried out according to the guidance of soil testing and fertilizer recommendations [16]. Soil moisture was oven dried at the temperature of $65{ }^{\circ} \mathrm{C}$ for $8 \mathrm{~h}$ (SG-GDJ50, SIOM, Shanghai, China). Soil $\mathrm{NO}_{3}{ }^{-}-\mathrm{N}_{\text {was }}$ detected with a UV-VIS spectrometer (UV2450, SHIMAZU, Kyoto, Japan) at 210 nm. $\mathrm{H}_{2} \mathrm{SO}_{4}$ (70\%) was applied to the soil extractant for acidification. The Total-N (TN) soil concentration was determined with Kjeldahl determination (KJELTEC 8400, FOSS, Hillerød, Denmark). Soil available phosphate (AP) was detected based on Molybdenum Blue Colorimetry at 660 nm (UV2450, SHIMAZU, Kyoto, Japan). The Organic Carbon (OC) concentration was measured based on dry combustion at $550{ }^{\circ} \mathrm{C}$ for $24 \mathrm{~h}$ (SG-SJ1700, SIOM, Shanghai, China). Flame photometry (420, Cole-Parmer, IL, USA) was used to measure the Available potassium (AK) content of the soil. Commercial nitrate ISE (No.9707BNWP, Thermo Scientific Orion, MA, USA) with a detection limit of $1.4 \mathrm{mg} / \mathrm{L}$ was also employed in this study.

The analytical grade chemicals used for the calibrations of ISE and the detection of standard soil macronutrients were purchased from Sinopharm Chemical Reagent Beijing Co. Ltd.

\subsection{Sensor Fusion Model}

The detected $\mathrm{NO}_{3}{ }^{-}-\mathrm{N}$ content would be greatly underestimated if soil moisture interference was not involved in the compensation of the sample net weight. In this study, volumetric soil moisture information was obtained during the on-site soil sampling. The volumetric moisture was converted into the gravimetric moisture for the correction of the sample's net (dry) weight. The detailed procedure was discussed in a previously published paper [15]. A sensor fusion model was designed for the $\mathrm{NO}_{3}{ }^{-}-\mathrm{N}$ prediction, as illustrated in Equations (1)-(3). Compared to the conventional Nernst model, the ratio of extractant to soil weight of the sensor fusion model achieved real-time correction instead of using a constant value, as used in most of the previous studies.

$$
\begin{gathered}
\omega=\frac{\rho_{w} \times\left(\theta-\theta_{0}\right)}{\rho_{s}}=\frac{1}{\rho_{s}} \times\left(\theta-\theta_{0}\right) \\
N=\omega+\frac{\omega m+m}{M} \\
C_{i}=1000 N \cdot A_{r} 10^{\frac{E-E_{0}}{s}}
\end{gathered}
$$

where $\rho_{s}$ represents the pre-determined bulk density of dry soil $\left(1.19 \mathrm{~g} / \mathrm{cm}^{3}\right) ; \rho_{w}$ represents the density of deionized water $(1.0 \mathrm{~g} / \mathrm{mL}) ; \theta_{0}$ represents the pre-determined volumetric moisture ratio $(-1.51 \%)$; $\theta$ represents the soil volumetric moisture (\%); $\omega$ represents the soil mass moisture (\%); $M$ represents the weight of the raw soil sample $(\mathrm{g}) ; m$ represents the volume of soil extractant $(\mathrm{mL})$; $N$ represents the ratio of extractant to the net weight of soil (mL/g); $A r$ represents the relative atomic mass, which, for nitrogen, is $14 ; C_{i}$ represents the concentration of nitrate in the tested sample $(\mathrm{m} / \mathrm{V}, \mathrm{mg} / \mathrm{L})$; $E$ represents the EMF value produced by ISE $(\mathrm{mV}) ; E_{0}$ represents the intercept potential of the Nernstian model of the tested ISE $(\mathrm{mV})$; and $S$ represents the response slope of the Nernstian model of the tested ISE (mV/decade), where decade means 10 times the change in the target concentration. 


\subsection{System Design}

The on-site soil $\mathrm{NO}_{3}{ }^{-}-\mathrm{N}$ detection bench consisted of five major units, including the extractant preparing unit (A), extractant clarification unit (B), electrode holder unit (C), leveling unit (D), and electronic control circuit unit (E), as illustrated in Figure 1a,b. Centrifuge (B9) was employed to achieve separation of the clarified extractant from the soil slurry. The centrifuge process was conducted at a speed of $1000 \mathrm{rpm}$ for $3 \mathrm{~min}$. The manually collected soil sample was weighed with electronic scales with a precision of $0.1 \mathrm{~g}$ (A10). Stepper motors of A1 and B1 were employed to achieve vertical movements of two mechanical arms for extractant injection and transportation. The proximity sensors of A5 and B4 were used to define the working scale of the vertical slide table (A3/B3). The precision of vertical movement was measured to be $0.05 \mathrm{~cm}$. Rotary table B7 was driven by step motor B7. Centrifuge B9 had 12 container positions, so B7 would rotate by 30 each time with a control precision of $0.5^{\circ}$. Transportation of DDW and the sample extract was achieved by peristaltic pumps A4/B5 through tubes of A6/A7. The stirring operation was performed with Blender A8. ISE testing was conducted by hanging the sensor on $\mathrm{C} 2$. To keep the balance of A10 and B9, the bench employed leveling meter D2, positioner D3, and screw adjuster E1.

The detection bench was manipulated in a programmable way by the self-designed electronic control circuit unit, as shown in Figure 1c. The STM 32 Microchip Controller Unit (MCU) was applied as the main processor. The underlying hardware of step motors 1-3 and peristaltic pumps 1-3 were motivated with the drive unit according to the pre-designated flowchart. A proximal sensing signal was sent to the MCU when the mechanical arms were close to the vertical limitation of $10 \mathrm{~cm}$. A Bluetooth connection was formed among the control circuit, ISE datalogger, and Android terminal devices, e.g., smartphones. Sensor readings and user commands were communicated. A schematic diagram of the circuit is illustrated in Figure 1c.

The rural smartphone popularity was reported to be $32 \%$ in China [17]. Considering the interface resource, flexible communication mode, convenient data storage, and upload capability, application software running on Android terminal devices was also developed in this study. The interface of the smartphone App is shown in Figure 1d. Predetermined soil sample profile information, including soil texture, bulk density, sample weight, DDW volume, and electroconductivity, should be input, saved, and downloaded to the control circuit. The parameters of the sample pretreatment operation, e.g., stirring time, rinsing method, and motor speed, are chosen according to the testing mode. Testing setups were employed with the calibration solution number, testing duration, sample number, file save option, and real-time display. A Location-Based Service (LBS) was embedded to provide the sample's geographic position. The Bluetooth setup was operated on the App.

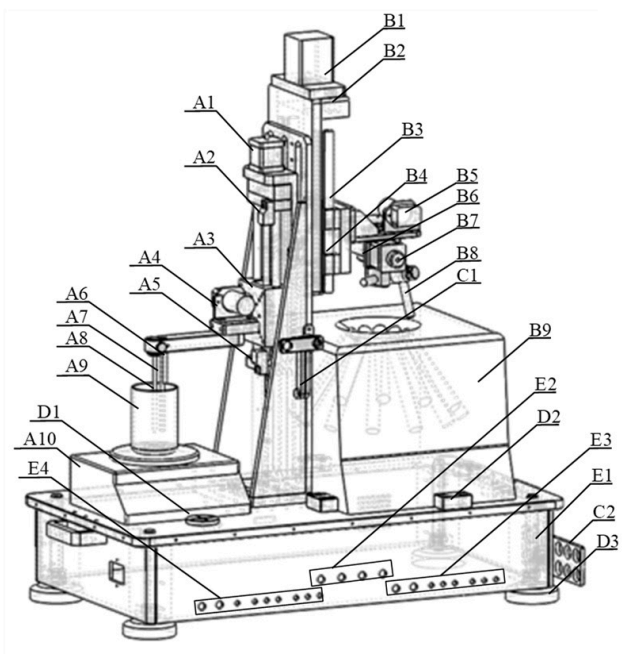

(a)

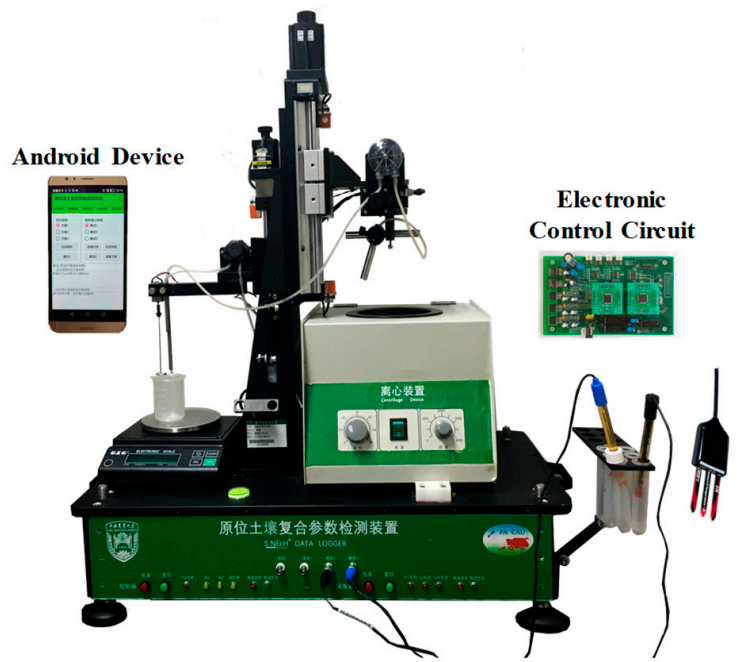

(b)

Figure 1. Cont. 


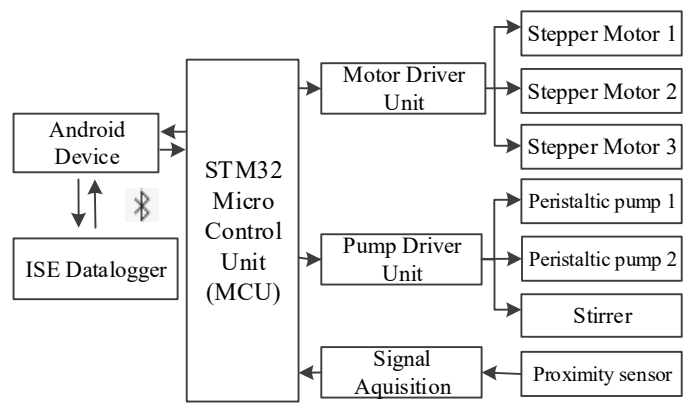

(c)
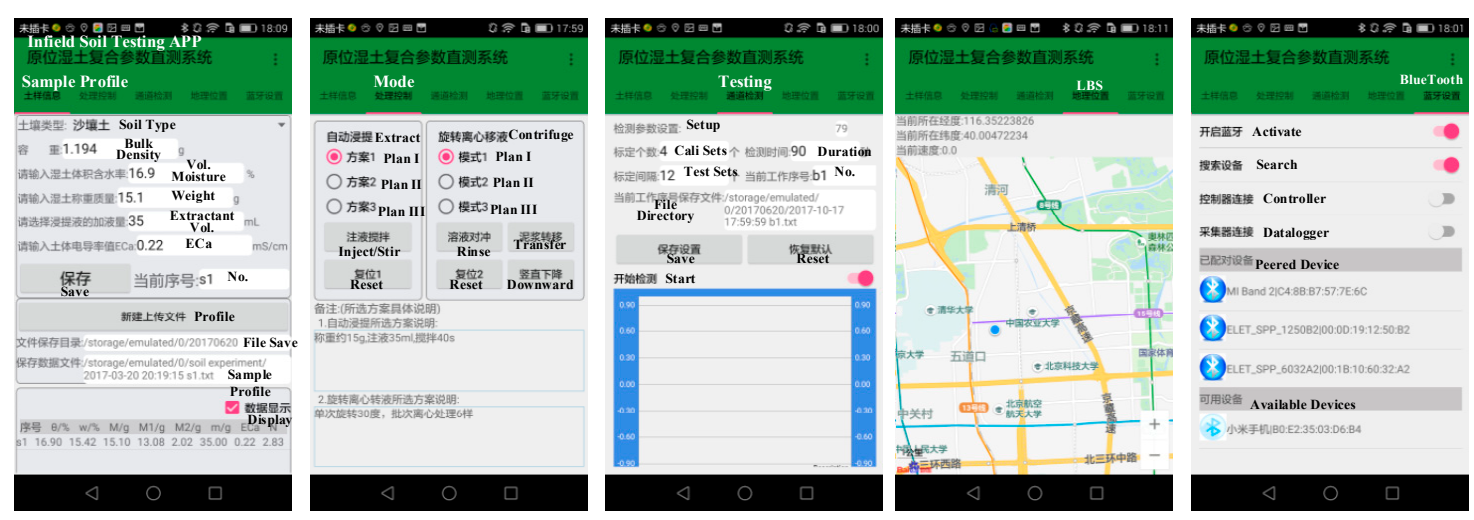

(d)

Figure 1. Diagram of the on-site detection bench: (a) System Design A1, Stepper motor 1 A2. Proximity sensor 1 A3, Vertical slide table 1 A4, Peristaltic pump A5, Proximity sensor 2 A6, Injecting tube A7, Outlet tube A8, Blender A9, Soil sample container A10, Electronic weight scale B1, Stepper motor 2 B2, Proximity sensor 3 B3, Vertical slide table 2 B4, Proximity sensor 4 B5, Peristaltic pump2 B6, Rotary table B7, Stepping motor 3 B8, Pipe hanger B9,Centrifuge C1, Electrode hanger 1 C2, Electrode hanger 2 D1, Horizontal Lever meter D2, Positioner D3, Leveling screw E1, Circuit controller E2, ISE connector E3, Control switches and indicator lights E4, Control switches and indicator lights; (b) Physical picture of the hardware; (c) Diagram of the Electric Control Circuit Design; (d) Android App for Smartphones.

\subsection{Field Test Design}

Fresh soil samples were manually collected at a depth of $0-25 \mathrm{~cm}$ from a demonstration summer corn planting farm $\left(70 \mathrm{~L} \times 24 \mathrm{~W} \mathrm{~m}^{2}\right)$ from April 30 to Aug 31, $2016\left(40^{\circ} 8^{\prime} 37^{\prime \prime} \mathrm{N}, 116^{\circ} 11^{\prime} 31^{\prime \prime} \mathrm{E}\right)$. Soil sampling information is shown in Figure 2. The cornfield was divided into 12 fertility zones with a varied $\mathrm{N}$ application rate from 0 to $3 \mathrm{~N}$, where $1 \mathrm{~N}$ equals the application of $375 \mathrm{~kg} / \mathrm{ha}$ of compound fertilizer (Total content $\geq 40 \%, \mathrm{~N}: \mathrm{P}_{2} \mathrm{O}_{5}: \mathrm{K}_{2} \mathrm{O}, 28 \%: 6 \%: 6 \%$, Shidanli Co. Ltd., Shandong, China) and $75 \mathrm{~kg} / \mathrm{ha}$ of urea; $\frac{1}{2} \mathrm{~N}$ represents half of the $1 \mathrm{~N}$ rate; $0 \mathrm{~N}$ means no fertility; and $3 \mathrm{~N}$ means triple the rate. A total of 11 groups of soil samples were collected. Raw soil samples, detected in the field by the self-designed bench without moisture compensation, were recorded as ISE $\mathrm{raw}_{\text {. }}$. ISE results, provided by the self-designed detection bench by the sensor fusion model, were recorded as ISEOS. Laboratory ISE soil testing results were labeled $\mathrm{ISE}_{\mathrm{LT}}$, in which soil samples was treated with conventional soil pretreatments. Soil samples measured by the standard UV-VIS spectrometer were provided by the soil testing center of China's Agricultural University. The nitrate-nitrogen content was recorded to be Stand Spec $_{\text {. }}$. 


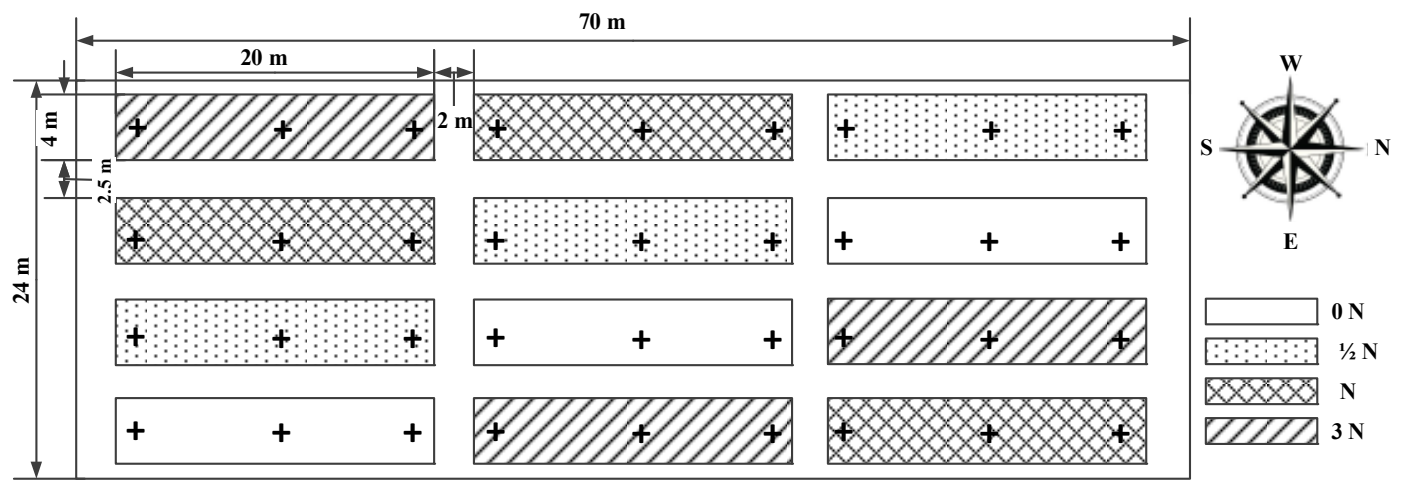

(a)

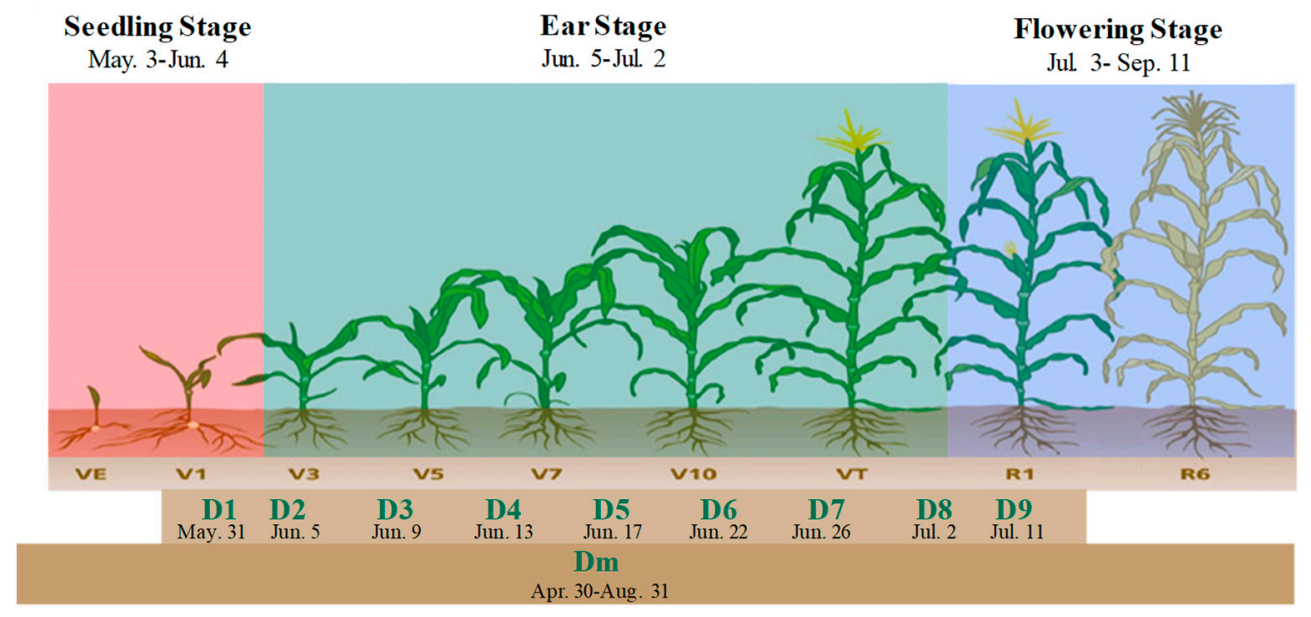

(b)

Figure 2. Soil Sampling Information: (a) Sampling space position inside the field (b) Sampling time.

Forty-two sets of raw samples, labeled as $\mathrm{D}_{\mathrm{m}}$, with broader time variance, were randomly sampled in the field from April 30 to August 31. The $D_{m}$ testing group was used to evaluate the performance of the designed sensor fusion model. Differences among Stand ${ }_{\mathrm{Spec}}, \mathrm{ISE}_{\mathrm{raw}}, \mathrm{ISE}_{\mathrm{OS}}$, and ISE $\mathrm{LT}_{\mathrm{LT}} \mathrm{were}$ compared. The evaluation results are illustrated as Figure 3.

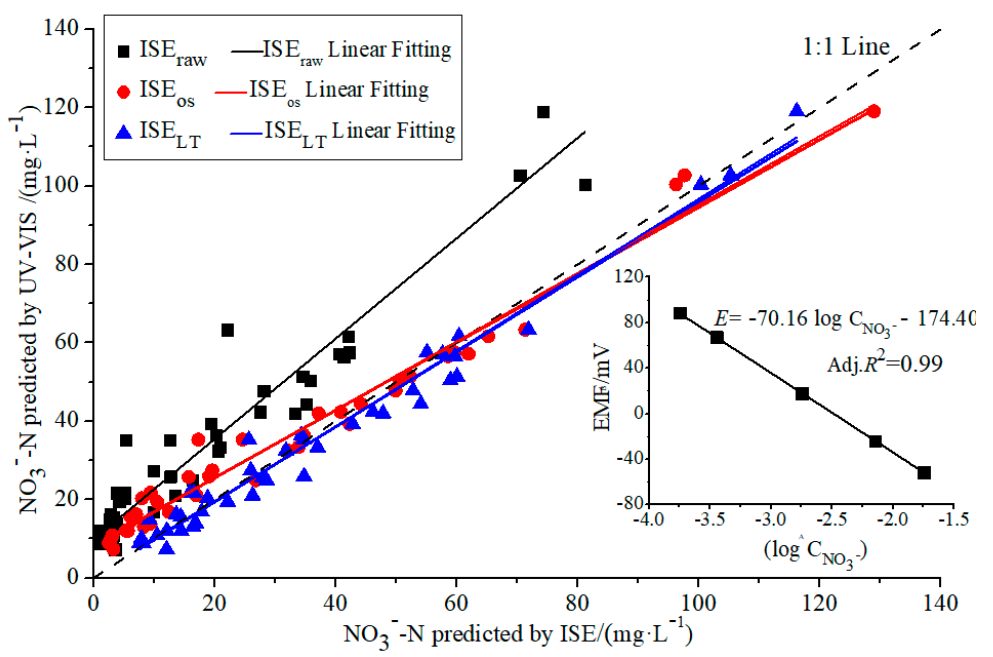

Figure 3. Comparison of soil $\mathrm{NO}_{3}{ }^{-}-\mathrm{N}$ predicted with $\mathrm{ISE}_{\mathrm{raw}}, \mathrm{ISE}_{\mathrm{OS}}$, and ISE. 
As demonstrated in Figure 2a, three sampling positions were marked with the plus cross icon in each of the 12 zones. One representative soil sample per zone was obtained by thoroughly mixing these three cores. A total number of 108 sets of fresh soil samples were collected for 42 days, which covered the summer corn growth stages from trifoliate to silking. The first 12 samples were collected on May 30 , which were labeled as group D1. Then, the 7 continuous groups of samples, marked D2-D8, were obtained from June 5 until July 2, commonly at intervals of 3 days. The last group of soil samples (D9) was collected on July 11 . Soil samples were applied to validate the feasibility of the on-site $\mathrm{NO}_{3}{ }^{-}-\mathrm{N}$ testing system.

The soil properties provided by the standard testing center are summarized in Table 1.

Table 1. Soil sample information.

\begin{tabular}{|c|c|c|c|c|c|c|c|}
\hline & No. & $\begin{array}{c}\text { Mass } \\
\text { Moisture }\end{array}$ & $\begin{array}{l}\text { Nitrate } \\
\text { Nitrogen } \\
\left(\mathrm{mg} \cdot \mathrm{L}^{-1}\right)\end{array}$ & $\begin{array}{c}\text { Total }-\mathrm{N}^{1} \\
\left(\mathrm{~g} \cdot \mathrm{kg}^{-1}\right)\end{array}$ & $\begin{array}{l}\text { Available-P } \\
{ }^{1}\left(\mathrm{mg} \cdot \mathrm{L}^{-1}\right)\end{array}$ & $\begin{array}{l}\text { Organic } \\
\text { Matter } 1 \\
\left(\mathbf{g} \cdot \mathbf{k g}^{-1}\right)\end{array}$ & $\begin{array}{l}\text { Available-K } \\
\left(\mathrm{mg} \cdot \mathrm{L}^{-1}\right)\end{array}$ \\
\hline $\mathrm{D}_{\mathrm{m}}$ & 42 & $2.5 \%-30.2 \%$ & $11.2-87.7$ & $0.3-10.5$ & $9.8-32.5$ & $3.2-9.0$ & $8.3-121.3$ \\
\hline D1 & 12 & $12.5 \%-16.3 \%$ & $33.1-159.8$ & $0.3-9.9$ & $2.4-43.3$ & $1.3-11.2$ & $10.3-98.8$ \\
\hline $\mathrm{D} 2$ & 12 & $13.3 \%-16.9 \%$ & $31.6-345.0$ & - & - & - & - \\
\hline D3 & 12 & $13.2 \%-17.6 \%$ & $27.5-272.0$ & - & - & - & - \\
\hline $\mathrm{D} 4$ & 12 & $11.4 \%-15.4 \%$ & $16.2-189.7$ & - & - & - & - \\
\hline D5 & 12 & $10.6 \%-13.7 \%$ & $19.3-260.5$ & - & - & - & - \\
\hline D6 & 12 & $9.2 \%-15.1 \%$ & $19.3-256.9$ & - & - & - & - \\
\hline D7 & 12 & $23.8 \%-26.4 \%$ & $12.9-72.3$ & - & - & - & - \\
\hline D8 & 12 & $14.3 \%-17.3 \%$ & $9.5-32.6$ & - & - & - & - \\
\hline D9 & 12 & $14.8 \%-18.1 \%$ & $5.2-16.7$ & - & - & - & - \\
\hline
\end{tabular}

${ }^{1}$ Soil Total-N, Available-P, Organic Matter, and Available-K were tested in two groups of soil samples. $\mathrm{D}_{\mathrm{m}}$ was 42 soil samples evaluated using the sensor fusion model. D1 was 12 samples used for the evaluation of the on-site bench. Detection was not conducted in D2-D9, because these soil properties were considered to be stable during the same corn growth season.

\section{Results and Discussion}

\subsection{Validation of the Sensor Fusion Model}

The sensor fusion compensation model, described in Equations (1)-(3), was evaluated with 42 soil samples, as demonstrated in Figure 3. The soil testing results of ISE $\mathrm{E}_{\text {raw }}$ were, on average,

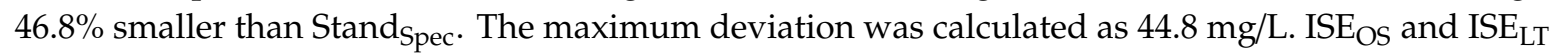
demonstrated a good correlation with the standard spectrometric results. Absolute error values of 0.2-17.2 and 0-9.8 mg/L were obtained, respectively. The measurement accuracy of ISE $O$ S was increased by more than $50 \%$ compared with that of ISE $_{\text {raw }}$. The soil moisture compensation model eliminated the testing error.

\subsection{Evaluation of the On-Site Soil $\mathrm{NO}_{3}{ }^{-}-\mathrm{N}$ Detection}

Soil $\mathrm{NO}_{3}{ }^{-}-\mathrm{N}$ detection results were compared among three different methods-standard spectrometric results, laboratory ISE testing, and on-site ISE based monitoring-as shown in Table 2. The testing efficiency was also evaluated. The time duration and the labor force consumed for dealing with a dozen soil samples were compared among UV-VIS, ISE $\mathrm{OS}_{\text {, }}$ and $\mathrm{ISE}_{\mathrm{LT}}$. The results are summarized in Table 3. 
Table 2. Statistical analysis of the linear regression fitting results.

\begin{tabular}{lccccccccc}
\hline & $\begin{array}{c}\text { Detection } \\
\text { Range } \\
\left(\mathbf{m g} \cdot \mathbf{L}^{-1}\right)\end{array}$ & $\begin{array}{c}\text { Linear Fitting } \\
\text { Model }\end{array}$ & Adj. $\boldsymbol{R}^{\mathbf{2}}$ & F-Value & $\boldsymbol{P}$-Value & Sig. & $\begin{array}{c}\text { AE } \\
\left(\mathbf{m g} \cdot \mathbf{L}^{-1}\right)\end{array}$ & $\begin{array}{c}\text { MRE } \\
\mathbf{( \% )}\end{array}$ & $\begin{array}{c}\text { RMSE } \\
\left(\mathbf{m g} \cdot \mathbf{L}^{-\mathbf{1}}\right)\end{array}$ \\
\hline $\mathrm{ISE}_{\mathrm{OS}}$ & $5.0-156.3$ & $\mathrm{y}=1.02 \mathrm{x}-0.57$ & 0.98 & 6055.8 & 0.0 & $*$ & $0.1-19.9$ & 13.9 & 6.1 \\
$\mathrm{ISE}_{\mathrm{LT}}$ & $5.9-150.5$ & $\mathrm{Y}=0.98 \mathrm{x}-0.71$ & 0.98 & 5488.9 & 0.0 & $*$ & $0.0-18.4$ & 13.7 & 5.5 \\
\hline
\end{tabular}

* represents that the linear fitting model is significant.

Table 3. Comparison of the testing duration and labor force among Stand $_{\mathrm{Spec}}$, ISE $\mathrm{OS}$, and ISE $\mathrm{LT}_{\mathrm{LT}}$

\begin{tabular}{|c|c|c|c|c|c|c|c|}
\hline \multicolumn{2}{|c|}{ Measurement $^{1}$} & \multicolumn{2}{|c|}{ Stand $_{\text {Spec }}$} & \multicolumn{2}{|l|}{ ISE $_{\mathrm{LT}}$} & \multicolumn{2}{|c|}{ ISE $_{\mathrm{OS}}$} \\
\hline \multirow{7}{*}{$\begin{array}{l}\text { Testing } \\
\text { Duration } \\
(\min )^{2}\end{array}$} & \multirow{7}{*}{ OPERATIONS } & $\begin{array}{l}\text { Quantitative } \\
\text { Weighing }\end{array}$ & 12 & $\begin{array}{c}\text { Quantitative } \\
\text { Weighing }\end{array}$ & 12 & $\begin{array}{c}\text { Sample } \\
\text { Weighing }\end{array}$ & 2 \\
\hline & & $\begin{array}{l}\text { Extractant } \\
\text { adding }\end{array}$ & 12 & $\begin{array}{l}\text { Extractant } \\
\text { adding }\end{array}$ & 12 & \multirow{2}{*}{$\begin{array}{l}\text { Extractant } \\
\text { Injection }\end{array}$} & \multirow{2}{*}{16} \\
\hline & & Shaking & 20 & Shaking & 20 & & \\
\hline & & Stabilization & 20 & Stabilization & 20 & \multirow{2}{*}{$\begin{array}{l}\text { Centrifuge } \\
\text { Filtration }\end{array}$} & \multirow{2}{*}{3} \\
\hline & & Titration & $\begin{array}{c}4 \\
24\end{array}$ & Filtration & 4 & & \\
\hline & & \multirow{2}{*}{$\begin{array}{l}\text { Detection } \\
\text { Total }\end{array}$} & 15 & Detection & 24 & \multirow[t]{2}{*}{ Detection } & 24 \\
\hline & & & 107 & & 92 & & 45 \\
\hline $\begin{array}{l}\text { Labor force } \\
\text { Intensity }\end{array}$ & & $\begin{array}{l}\text { Intensive phy } \\
\text { work. Participa } \\
\text { the overall pr }\end{array}$ & $\begin{array}{l}\text { cal } \\
\text { in in } \\
\text { ess }\end{array}$ & $\begin{array}{l}\text { Intensive phy } \\
\text { work. Participa } \\
\text { the overall pr }\end{array}$ & $\begin{array}{l}\mathrm{al} \\
\mathrm{n} \text { in } \\
\mathrm{ss}\end{array}$ & $\begin{array}{l}\text { Light physica } \\
\text { Participation i } \\
\text { pickup and we }\end{array}$ & $\begin{array}{l}\text { ork. } \\
\text { nple } \\
\text { ting. }\end{array}$ \\
\hline
\end{tabular}

\footnotetext{
${ }^{1}$ Soil samples detected by $\mathrm{Stand}_{\mathrm{Spec}}$ and $\mathrm{ISE}_{\mathrm{LT}}$ should be pretreated according to the soil testing recommendations. The shaking time required is $20 \mathrm{~min}$. The optimal stabilization time is $20 \mathrm{~min}$.; Soil samples detected by ISE $\mathrm{OS}$ did not undergo quantitative weighting. Fresh soil samples were first weighed after moisture measurement. A peristaltic pump was used for extractant injection. The extractant injection rate was $36 \mathrm{~s} / \mathrm{sample}$. The stirring process was used for $40 \mathrm{~s} / \mathrm{sample}$. The centrifuge filtration rate was $40 \mathrm{~s} / 12$ samples. A stable ISE reading was obtained when the variation of EMF less was than $\pm 1 \mathrm{mV}$. The ISE detection rate was $4-5 \mathrm{~min} / \mathrm{sample} .{ }^{2}$ Time used for processing 12 soil samples.
}

As illustrated in Table 2, the linear regression fitting results of ISE $_{\mathrm{OS}}, \mathrm{ISE}_{\mathrm{LT}}$, and UV-VIS were $y_{U V \text { VIS }}=1.02 I S E_{O S}-0.57, y_{U V \text { VIS }}=0.98 I S E_{L T}-0.71$. Both linear fitting curves were close to the 1:1 line. The ISE detection accuracy demonstrated a slight variation with the change in soil $\mathrm{NO}_{3}{ }^{-}-\mathrm{N}$ content. The accuracy was derived as $\pm 30 \%, \pm 16 \%$ and $5 \%$ (Full Scale, FS) at the $\mathrm{NO}_{3}{ }^{-}-\mathrm{N}$ content ranges of $0-30,31-90$, and $91-200 \mathrm{mg} / \mathrm{L}$, respectively. The maximum error (with the possibility of $\pm 90 \%$ ) was less than $10 \mathrm{mg} / \mathrm{L}$. The intersection was close to 1 . Adj. $R^{2}$ values were both 0.98 . The ISE results demonstrated close consistency with UV-VIS. The absolute error values among ISE $\mathrm{OS}_{\mathrm{ISE}} \mathrm{IST}_{\mathrm{LT}}$ and UV-VIS were calculated to be $0.1-19.9$ and $0.0-18.4 \mathrm{mg} / \mathrm{L}$ with average values of 4.7 and $4.0 \mathrm{mg} \cdot \mathrm{L}^{-1}$, respectively. The RMSEs were found to be 6.1 and $5.5 \mathrm{mg} / \mathrm{L}$. No significant difference was found between the results of $\mathrm{ISE}_{\mathrm{OS}}$ and $\mathrm{ISE}_{\mathrm{LT}}$.

The ISE $\mathrm{OS}$ demonstrated obvious advantages in terms of the testing efficiency and labor force intensity, as shown in Table 3. Compared with the conventional soil pretreatment protocols conducted before UV-VIS and ISE $\mathrm{LT}_{\mathrm{LT}}$, the self-designed on-site detection bench was decreased by 45 mins. The total time consumption was reduced to $40 \%$ of the duration of the conventional spectrometry method.

Integrated with the multi-sensor, centrifuge filtration, and programmable fluidic control, the self-designed on-site soil $\mathrm{NO}_{3}{ }^{-}-\mathrm{N}$ detection bench produced a reliable result with an efficient operation, which demonstrated a promising perspective for the infield monitoring applications.

\section{3. $\mathrm{NO}_{3}{ }^{-}-\mathrm{N}$ Variation Monitoring}

Based on the workbench, the on-site $\mathrm{NO}_{3}{ }^{-} \mathrm{N}$ variation was monitored from the trifoliate stage to the silking stage of summer corn. Samples collected from three $1 \mathrm{~N}$ zones were selected to demonstrate the $\mathrm{NO}_{3}{ }^{-}-\mathrm{N}$ content change with corn growth, as shown in Figure 4. The $\mathrm{NO}_{3}{ }^{-}-\mathrm{N}$ content was at 
a level of around 70-100 mg/L at the beginning of D1. $\mathrm{NO}_{3}{ }^{-}-\mathrm{N}$ demonstrated great variation in characteristics with time and at different sample sites. However, an obvious $\mathrm{NO}_{3}{ }^{-}-\mathrm{N}$ decrease occurred uniformly at an amplitude of $80 \mathrm{mg} / \mathrm{L}$ across all three testing sites from D6 to D7. According to the definition of corn growth, D6 was the $\mathrm{V}_{\mathrm{T}}$ period and $\mathrm{D} 7$ was in the $\mathrm{R}_{1}$ period, as shown in Figure $2 \mathrm{~b}$. The monitoring results perfectly fit the nitrogen growth law of corn. After that growth stage, no clear nitrogen absorption was verified. The $\mathrm{NO}_{3}{ }^{-}-\mathrm{N}$ content stayed at the level of $13.2-17.0 \mathrm{mg} / \mathrm{L}$.

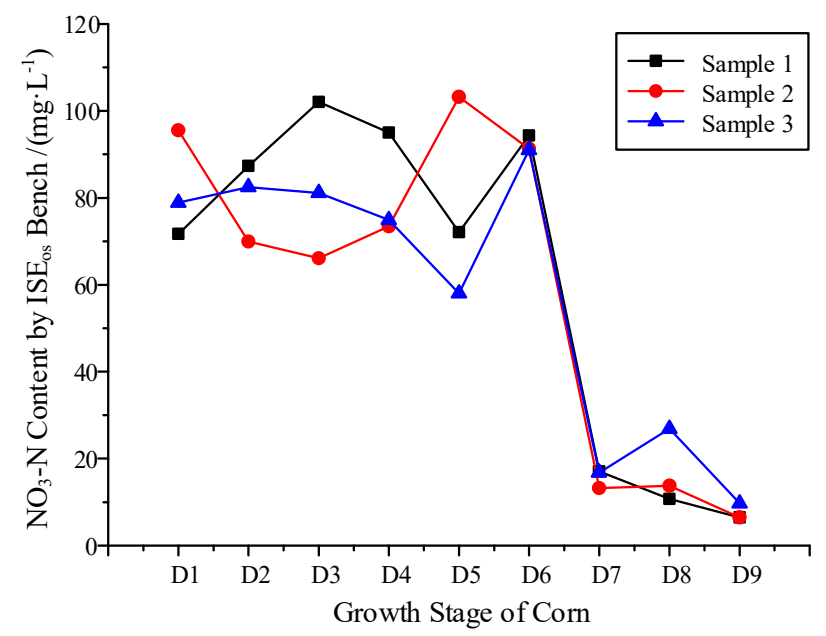

Figure 4. Monitoring of $\mathrm{NO}_{3}{ }^{-}-\mathrm{N}$ Variation by the On-site detection Bench.

\section{Conclusions}

In this paper, a self-designed prototype system for on-site soil $\mathrm{NO}_{3}{ }^{-}-\mathrm{N}$ detection based on ISE was designed and tested. Sensor fusion of ISE and a moisture sensor effectively eliminated $50 \%$ of the testing error. The performance of the on-site soil $\mathrm{NO}_{3}{ }^{-}-\mathrm{N}$ system demonstrated good consistency with the UV-VIS testing and laboratory ISE testing methods. Compared with the UV-VIS method, the average absolute error was determined to be $4.7 \mathrm{mg} \cdot \mathrm{L}^{-1}$. The RMSE was found to be $6.1 \mathrm{mg} / \mathrm{L}$. In addition, the detection duration decreased to $40 \%$ of that of the spectrometric method.

Author Contributions: Conceptualization, Y.L. and M.Z.; Methodology, Y.L. and M.Z.; Software, Y.L. and Q.Y.; Validation, Y.L., Q.Y. and M.C.; Formal Analysis, Y.L. and M.Z.; Investigation, Y.L. and M.Z.; Resources, M.W. and M.Z.; Data Curation, Y.L. and M.Z.; Writing-Original Draft Preparation, Y.L. and M.Z.; Writing-Review \& Editing, Y.L. and M.Z.; Visualization, Y.L. and Q.Y.; Supervision, M.Z.; Project Administration, M.W. and M.Z.; Funding Acquisition, M.W. and M.Z.

Funding: This research was financially supported by the National Key Research and Development Program (Grant No. 2016YFD0700300-2016YFD0700304 \& 2016YFD0800900-2016YFD0800907) and Key Laboratory of Technology Integration and Application in Agricultural Internet of Things, Ministry of Agriculture, P. R. China (2016KL03).

Conflicts of Interest: The authors declare no conflict of interest.

\section{References}

1. Myers, R.J.K.; Paul, E.A. Nitrate ion electrode method for soil nitrate-nitrogen determination. Can. J. Soil Sci. 1968, 48, 369-371. [CrossRef]

2. Thottan, J.; Adsett, J.F.; Sibley, K.J.; Macleod, C.M. Laboratory evaluation of the ion selective electrode for use in an automated soil nitrate monitoring system. Commun. Soil Sci. Plant Anal. 1994, 25, 3025-3034. [CrossRef]

3. Sibley, K.J.; Adsett, J.F.; Struik, P.C. An on-the-go-soil sampler for an automated soil nitrate mapping system. Trans. ASABE 2008, 51, 1895-1904. [CrossRef]

4. Sibley, K.J.; Astatkie, T.; Brewster, G.; Struik, P.C.; Adsett, J.F.; Pruski, K. Field-scale validation of an automated soil nitrate extraction and measurement system. Precis. Agric. 2009, 10, 162-174. [CrossRef] 
5. Davenport, J.R.; Jabro, J.D. Assessment of hand held ion selective electrode technology for direct measurement of soil chemical properties. Commun. Soil Sci. Plant Anal. 2001, 32, 3077-3085. [CrossRef]

6. Kim, H.J.; Hummel, J.W.; Birrell, S.J. Evaluation of nitrate and potassium ion-selective membranes for soil macronutrient sensing. Trans. ASABE 2006, 49, 597-606. [CrossRef]

7. Kim, H.J.; Hummel, J.W.; Sudduth, K.A.; Motavalli, P.P. Simultaneous Analysis of Soil Macronutrients Using Ion Selective Electrodes. Soil Sci. Soc. Am. J. 2006, 71, 1867-1877. [CrossRef]

8. Adamchuk, V.I.; Lund, E.D.; Dobermann, A.; Morgan, M.T. On-the-go mapping of soil properties using ion-selective electrodes. In Precision Agriculture; John, V.S., Armin, W., Eds.; Wageningen Academic Publishers: Wagenin, The Netherlands, 2003; pp. 27-33.

9. Adamchuk, V.I.; Lund, E.D.; Sethuramasamyraja, B.; Morgan, M.T. Direct measurement of soil chemical properties on-the-go using ion-selective electrodes. Comput. Electron. Agric. 2005, 48, 272-294. [CrossRef]

10. Sethuramasamyraja, B.; Adamchuk, V.I.; Dobermann, A.; Marx, D.B.; Jones, D.D.; Meyer, G.E. Agitated soil measurement method for integrated on-the-go mapping of soil $\mathrm{pH}$, potassium and nitrate contents. Comput. Electron. Agric. 2008, 60, 212-225. [CrossRef]

11. Adamchuk, V.; Dhawale, N.; Renelaforest, F. Development of an on-the-spot analyzer for measuring soil chemical properties. In Proceedings of the International Conference on Precision Agriculture, Sacramento, CA, USA, 20-23 July 2014.

12. Zhang, L.; Zhang, M.; Ren, H.; Pu, P.; Kong, P.; Zhao, H. Comparative Investigation on Soil Nitrate-nitrogen and Available Potassium Measurement Capability by Using Solid-State and PVC ISE. Comput. Electron. Agric. 2015, 112, 83-91. [CrossRef]

13. Zhang, L. Study on Establishing the Electrochemical Methods for Fast Determination of Soil Available Macronutrients Based on Ion-Selective Electrodes. Ph.D. Thesis, China Agricultural University, Beijing, China, 2015. (In Chinese with English Abstract).

14. Kong, P.; Zhang, M.; Ren, H.; Li, Y.; Pu, P. Rapid Pretreatment Method for Soil Nitrate Nitrogen Detection based on Ion-selective Electrode. Trans. Chin. Soc. Agric. Mach. 2015, 46, 102-107, (In Chinese with English Abstract).

15. Li, Y.; Zhang, M.; Pan, L.; Zheng, J. ISE-base Sensor Fusion Method for Wet Soil Nitrate-nitrogen Detection. Trans. Chin. Soc. Agric. Mach. 2016, 47, 285-290, (In Chinese with English Abstract).

16. Bai, Y.L.; Yang, L.P. Soil testing and fertilizer recommendation in Chinese agriculture. Soil Fertil. Sci. China 2006, 2, 3-7, (In Chinese with English Abstract).

17. Cyberspace Administration of China. The 44th China Statistical Report on Internet Development. Available online: http://www.cac.gov.cn/2019-08/30/c_1124938750.htm (accessed on 30 August 2019). 